\title{
AS MULHERES NAS LETRAS DAS MARCHINHAS CARNAVALESCAS \\ (1930-1940)
}

Ronald Clay dos Santos Ericeira (UFRRJ)

Identificando nas composições de Lamartine Babo, de Braguinha e de Ari Barroso visões sociais sobre as mulheres no Rio de Janeiro nas décadas de 1930 e 1940, o texto insere as letras das marchinhas carnavalescas como lugar privilegiado para o entendimento de uma parcela do pensamento social brasileiro no período getulista.

MARCHINHA; MULHERES; COMPOSITORES; RIO DE JANEIRO.

ERICEIRA, Ronald Clay dos Santos. As mulheres nas letras das marchinhas carnavalescas (19301940). Textos escolhidos de cultura e arte populares, Rio de Janeiro, v.10, n.2, p. 93-107, nov. 2013. 


\section{WOMEN IN CARNIVAL MUSIC LYRICS (1930-1940)}

Ronald Clay dos Santos Ericeira (UFRRJ)

By identifying social views on women in Rio de Janeiro in the 1930s and 1940s in the musical production of Lamartine Babo, Braguinha and Ari Barroso, the text establishes the lyrics of carnival music as a privileged space for the understanding of a portion of the Brazilian social thought during the Vargas years.

MARCHINHAS; WOMEN; COMPOSERS; RIO DE JANEIRO.

ERICEIRA, Ronald Clay dos Santos. As mulheres nas letras das marchinhas carnavalescas (19301940). Textos escolhidos de cultura e arte populares, Rio de Janeiro, v.10, n.2, p. 93-107, nov. 2013. 


\section{INTRODUÇÃO}

Em uma perspectiva sociológica, DaMatta (1994) assevera que as músicas de carnaval ajudam a pensar o Brasil. Tais canções se difundem em todas as camadas sociais, transpondo fronteiras econômicas, etárias e sexuais, sendo, portanto, instrumentos simbólicos pelos quais os compositores encontram meios para dramatizar os valores sociais da sociedade brasileira e suas relações de poder, bem como para aludir a questões referentes ao relacionamento entre homens e mulheres no país.

A despeito dessa relevância das músicas de carnaval para desvelar fundamentos identitários de nosso país, seu estudo deixa a desejar, havendo poucos trabalhos científicos publicados. Notadamente, o samba tem despertado mais interesse dos acadêmicos brasileiros como indicam algumas teses e dissertações já escritas sobre o assunto. Por outro lado, as pesquisas sobre marchinhas são quase inexistentes. Assim, pareceu-me desafiante desvelar uma parcela dos sentidos sociais encobertos pelas marchinhas, particularmente as compostas entre 1930 e 1940.

A justificativa para esse recorte temporal advém de diversos fatores. O primeiro calca-se no fato de esse período de tempo ser apontado por pesquisadores como a fase dourada das marchinhas no Brasil (TINHORÃo, 1997; ALENCAR, 1979). Nas décadas subsequentes, o samba coloniza o país, tornando-se a música brasileira por excelência. Antes dessa colonização cultural exercida pelo samba, as marchinhas eram um dos principais veículos transmissores de mensagens sociais. Outra razão para a delimitação temporal desse objeto de investigação é de ordem metodológica. Levar a cabo uma pesquisa acadêmica tendo como parâmetro de investigação o período de 1930 a 1940 foi mais exequível do que pretender abarcar quase 90 anos de história das marchinhas no Brasil.

Nos primeiros levantamentos desta pesquisa três dados me chamaram a atenção: primeiro, a totalidade das canções era de autoria masculina; segundo, a maioria dos compositores pertencia às camadas médias cariocas; o terceiro aspecto, e talvez o mais relevante para os objetivos deste texto, refere-se ao fato de essas músicas apresentarem amiúde temas relacionados com as mulheres. Nessa abordagem inicial, os temas identificados foram variados: a aparência física da mulher, assim como sua honra e seu comportamento sexual são exemplos.

Nessa perspectiva, procurei trazer à baila o modo pelo qual as mulheres foram representadas na obra de três compositores de marchinhas: Lamartine Babo, Ari Barroso e Braguinha. A delimitação da produção musical desses autores deu-se por dois motivos específicos. Primeiramente, oriundos de realidades 
socioeconômicas semelhantes, eles puderam ser classificados como representantes dos segmentos médios cariocas das décadas de 1930 e 1940 . Esse aspecto econômico comum aos três facilitou a definição do lugar social do qual falavam a respeito do universo feminino. Segundo, eles são considerados pelos historiadores da música popular os mais prolíferos produtores de marchinhas do país, sendo suas composições executadas até hoje nos dias de Momo.

Neste texto, meu objetivo foi refletir sobre os seguintes questionamentos: quais os sentidos atribuídos às mulheres nas letras de marchinha no transcurso das décadas de 1930 e 1940? Como essas canções reproduziam as experiências de homens e mulheres no Rio de Janeiro naquele período?

\section{AS MARCHINHAS E O CARNAVAL CARIOCA}

Os historiadores do carnaval carioca frisam que, até o final do século XIX, não havia músicas específicas para o folguedo de Momo. Os grupos carnavalescos saíam pelas ruas cantando e dançando livremente maxixes, habaneras, modinhas, valsas e polcas. Em 1899, porém, é composta a marcha-rancho “Ó abrealas". Essa foi a primeira música composta conscientemente para ser cantada durante o tríduo momesco, feita pela maestrina Chiquinha Gonzaga para o cordão carnavalesco Rosa de Ouro (DINIz, 1999). Cabe observar que aquela canção foi composta especificamente para aquele grupo carnavalesco e não para o deleite da sociedade mais ampla. As músicas de carnaval só efetivamente passaram a ser produzidas em larga escala, para serem cantadas pelo povo nas ruas, entre 1910 e 1920 (MORAES, 1959).

A biografia escrita por Jairo Severiano (1991) sobre o compositor João de Barro - o Braguinha - traz à baila a assertiva de que a marchinha seria um produto cultural das camadas médias urbanas cariocas. Elas se teriam consolidado como gênero musical na década de 1920. Nesse período, Freire Junior, José Francisco de Freitas e Eduardo Souto, músicos do teatro de revista da época, idealizaram um estilo de canção baseado em um ritmo alegre, em melodias simples e em letras curtas e jocosas (p.30).

Por sua vez, Alencar (1979) afirma que as marchinhas carnavalescas seriam oriundas de uma mistura musical entre a polca e duas danças norte-americanas - o one-step e o rag-time-difundidas no Rio de Janeiro entre 1910 e 1920. Ressalto que a primeira marchinha a fazer sucesso no carnaval carioca foi "Pé de anjo", em 1920, de Sinhô. Com efeito, essa composição estava inserida em peça teatral homônima. Foi, aliás, o sucesso da peça que disseminou a marchinha junto ao grande público. Convém acrescentar que a popularização das marchinhas carnavalescas só foi possível, entre outros fatores históricos, pelos concursos de 
músicas populares que aconteciam na cidade do Rio de Janeiro desde 1919 (ERICEIRA, 2010).

Depois de 1931, a prefeitura da cidade passou a organizar regularmente tais concursos, cujas canções participantes eram divulgadas nos meios de comunicação. A oficialização dos concursos e os incentivos financeiros oferecidos pela administração municipal aos vencedores acarretaram ampla comercialização das músicas de carnaval, emergindo, nesse transcurso, representativa parcela de intérpretes e compositores dessa canções, como Carmen Miranda, Mário Reis, João de Barro, Lamartine Babo, entre outros (SEVERIANO, 1991). Várias marchinhas, que até hoje são cantadas durante o reinado de Momo, surgiram nessa época. As mais conhecidas seriam: "O teu cabelo não nega", de Lamartine Babo; "Pierrô apaixonado", de Noel Rosa; "A mulata é a tal”, de Braguinha.

Neste ponto, destaco ainda os papéis exercidos pelo teatro de revista, pelo rádio e pelo cinema na divulgação das marchinhas carnavalescas. Programas de auditório, como Calouros em desfile, apresentado por Ari Barroso na Rádio Tupi e os filmes com temática momesca, como A voz do carnaval (1933); Alô, alô, carnaval (1936) e Banana da terra (1939), foram importantes para que as marchinhas, malgrado expressassem o pensamento dos segmentos médios cariocas sobre os eventos cotidianos, passasem a gozar de aceitação em todas as camadas sociais.

Comentando e satirizando os comportamentos e os valores sociais, as marchinhas ajudaram a promover o carnaval do Rio de Janeiro. É marchinha, aliás, a canção considerada o hino da então capital federal - "Cidade maravilhosa", de André Filho. Apesar de perder espaço social para os sambas-enredo a partir de 1950, as marchinhas ajudaram a escrever um importante capítulo da música popular brasileira.

\section{BAKHTIN E A LINGUAGEM CARNAVALESCA}

Neste estudo, priorizei as técnicas qualitativas e as teorias que concebem a imbricação inconteste entre linguagem e contexto social. No Brasil, os trabaIhos acadêmicos voltados para a análise das mensagens sociais contidas em letras de músicas foram empreendidos, em sua maioria, por psicanalistas, antropólogos e historiadores. Cabe, então, um questionamento: com examinar as letras das marchinhas em uma perspectiva socioantropológica? Entre os vários eixos teóricos possíveis, decidi empregar como instrumental de pesquisa as reflexões de Mikhail Bakhtin (1986) sobre a linguagem. Suas proposições teóricas ajudaram na condução de certos aspectos teóricos e metodológicos deste estudo. No que tange à dimensão teórica, as conjecturas bakhtinianas contribuíram na dissolução de possíveis tensões relacionadas aos "talentos individuais dos compositores 
das marchinhas" e o contexto social vigente na época. Acreditar que a inspiração de suas obras se formou unicamente de seu psiquismo seria negar o caráter dialógico do pensamento humano.

Para Bakhtin (1986), a consciência individual é fenômeno essencialmente social, pois, desde sua origem, está submetida às leis dos sistemas ideológicos vigorantes. O centro organizador de todo pensamento e de toda linguagem não é interno, mas externo à consciência. Ele está situado nas teias sociais que envolvem o indivíduo, resultando na explicação do funcionamento do psiquismo humano por fatores exclusivamente sociais. As enunciações individuais, aliás, seriam produtos dos conteúdos circulantes na vida social. Os conteúdos ideológicos não se encontrariam na alma dos indivíduos, mas exteriorizados, em suas palavras, seus gestos, suas ações. Em outros termos, "todo conteúdo ideológico pode ser compreendido e psiquicamente assimilado, isto é, transmitido por intermédio de signos interiores" (p. 49).

Não diminuindo o talento musical de Lamartine Babo, Ari Barroso e Braguinha, entendo suas composições como uma das formas jocosas que a sociedade carioca encontrou para comunicar suas percepções sobre as mulheres no Rio de Janeiro das décadas de 1930-1940. Declarada a filiação teórica, cabe agora aprofundar como as premissas teóricas bakhtinianas contribuíram para a construção do objeto de estudo aqui apresentado.

Para Bakhtin (1986), o exame dos diferentes tipos de linguagem deve ser colocado em prática por meio de duas perspectivas analíticas. A primeira, do ponto de vista do conteúdo, dos temas que se encontram circulando no tecido social. A segunda, do ponto de vista das formas de discursos através dos quais esses temas são pensados e comentados socialmente. $\mathrm{O}$ autor acrescenta ainda que cada época tem seu repertório de tipos de discursos usado em sua comunicação socioideológica. A proposta bakhtiniana é analisar concomitantemente o texto e o contexto (CASTRO, 2005, p.18). Assim, a tarefa intelectualmente desafiadora é desvelar não apenas as formas linguísticas que entram em cena no ato da enunciação, mas captar os significados sociais atribuídos a determinados temas frente às condições de um dado momento histórico.

Adotando essa premissa, realizei uma parcela dos procedimentos necessários para a investigação aqui pretendida, qual seja: o tema da pesquisa diz respeito aos significados sociais atribuídos às mulheres no Rio de Janeiro durante as décadas de 1930 e 1940. A segunda tarefa implicou a interpretação desses temas - os significados sociais - a partir da perspectivas das marchinhas. Nessa direção, considerei mister entendê-las como uma forma de discurso que a sociedade da época encontrou para comunicar seus valores e seus costumes. Na pers- 
pectiva bakhtiniana, a linguagem carnavalesca está associada à cultura cômicopopular, que se opõe aos tons formais das culturas religiosas e políticas oficiais. Tal linguagem seria dominada pelas paródias, ironias e risos. Bakhtin (1996, p. 10) acrescenta que a linguagem carnavalesca se constrói parodiando a vida ordinária. Todavia, "é preciso assinalar que a paródia carnavalesca está muito distante da paródia moderna puramente negativa e formal; com efeito, mesmo negando, aquela ressuscita e renova ao mesmo tempo. A negação pura é alheia à cultura popular".

Baseando-me nos referenciais bakhtinianos, examinei as marchinhas como uma forma de discurso cujas enunciações estão abertas ao riso e às paródias festivas. Embora suas execuções e produções circulem principalmente no período momesmo, seus temas podem variar dentro de um espectro de diversos assuntos, entre eles, o universo feminino. Do mesmo modo, os postulados de Bakhtin (1996) foram fundamentais também para organizar e interpretar o material coletado, bem como permitiram classificar os conteúdos das letras das marchinhas carnavalescas a partir de categorias temáticas.

\section{EXAMINANDO AS LETRAS DAS MARCHINHAS CARNAVALESCAS}

Não foi fácil realizar o levantamento do repertório de marchinhas compostas por Ari Barroso, Lamartine Babo e Braguinha cujos núcleos temáticos se referiam às mulheres. Tratando-se de canções produzidas nas décadas de 1930 e 1940, muitas estão fora de circulação comercial desde que o gênero perdeu espaço para o samba junto às gravadoras de disco do Rio de Janeiro e de São Paulo. Recentemente apenas as marchinhas mais conhecidas chegaram ao conhecimento do grande público, graças à reedição feita por artistas que, por sua vez, não estão ligados diretamente à divulgação de músicas carnavalescas, como a cantora Beth Carvalho. No que tange ao processo de análise das 43 músicas coletadas, identifiquei dois campos semânticos, bem como elaborei algumas categorias temáticas para nortear a interpretação qualitativa dos dados. Quanto aos campos semânticos, observei que dois temas sobressaíam dos demais: a definição da muIher por meio de algum aspecto físico ou natural, e as percepções das diferentes formas de relacionamento entre homens e mulheres.

No material coletado, é significativo o número de versos que nomeiam as mulheres pela tonalidade da pele ou pela etnia a que pertencem. A mulher era vista ou mencionada por um aspecto biológico. Por exemplo, a categoria cabelo foi empregada como uma espécie de metonímia das mulheres. Ademais, louras, 
morenas e mulatas pareciam disputar a preferência estética de Lamartine Babo, de Ari Barroso e de Braguinha. Eis dois trechos:

Amei a mulatinha, amei a moreninha, em 32... em 33 A loura namorei um mês. Agora eu fico com a melhor das três. Só porque o cabelo não negava, toda a gente só falava na mulata original... ("A melhor das três", de Lamartine Babo).

O teu cabelo não nega mulata, porque és mulata na cor, mas como a cor não pega mulata, mulata, eu quero teu amor... ("O teu cabelo não nega", de Lamartine Babo).

Poderia citar outros trechos em que a referência às mulheres acontece por meio da alusão à raça ou à tonalidade da cútis feminina. No entanto, creio que as menções acima são suficientes para afirmar que tais canções não podem ser compreendidas fora da conjuntura cultural da época, pois, na década de 1930, o pensamento social brasileiro reformulava positivamente a visão sobre a mestiçagem nacional (FREYRE, 1981). Outrora usada como explicação para o atraso intelectual e econômico do Brasil, a miscigenação passou a ser valorizada como elemento de alteridade da identidade brasileira. Nesse bojo, a mulata e o mestiço foram alçados ao patamar de ícones nacionais.

Nesse contexto de valorização da mestiçagem como elemento definidor da identidade brasileira, os compositores aderiram a esse discurso social, elegendo a morena como a cor que melhor define a mulher nacional. A loura, apesar de sua beleza, era considerada representante de terras estrangeiras. No entanto, ela poderia ficar com a cor nacional, caso viesse a habitar o país. Uma canção é exemplar na transmissão dessa mensagem:

Loura...que vens de outra terra..., quero te dar o meu amor mais quente, do que o sol ardente deste meu país. Linda Lourinha, tens o olhar tão claro, deste azul tão raro, como um céu de anil, mas as tuas faces, vão ficar morenas, como as pequenas deste meu Brasil ("Linda lourinha", de Braguinha).

Outro conjunto de letras definindo as mulheres pela perspectiva biológica é concernente aos dotes e à beleza feminina. Nesse espectro semântico, são reiteradamente registrados os elogios a alguma parte do corpo das mulheres. Vejamos alguns versos:

Quando Mimi! Linda Mimi! Dos olhos que parecem pintadinhos de nanquim. Mimi! Não sei se eu vi num quadro de Xangai ou num vaso de Pequim. E como seu tipinho, no Brasil não há... (“Linda Mimi", de Braguinha). 
Ela bole com seus quadris, eu bato palmas e peço bis. Ai, mulata, cor de canela! Salve, salve, salve, salve, salve, ela! (“A mulata é a tal", de Braguinha).

Além de assimilar a discussão em torno da mestiçagem em voga no país na década de 1930, acredito que a profusão de citações aos aspectos físicos da muIher presentes nas letras das marchinhas reflete também o ponto de vista masculino que concebe a mulher enquanto um ser biológico, e não como um ser social dotado de capacidade intelectual ou de aptidão para o trabalho.

Seguindo também uma perspectiva biologizante, em várias composições a mulher é associada a objetos e a seres naturais. Nas letras dessas marchinhas, são recorrentes os usos de metáforas e de comparações entre a mulher e determinados elementos da natureza. Não foi raro encontrar citações por meio das quais a mulher-natureza é exaltada pela sua beleza física. Eis um exemplo: “

Louras, cor de laranjas cem mil. Salve! Salve! Meu carnaval, Brasil! Salve a lourinha dos olhos verdes, cor das nossas matas. Salve a mulata! Cor de café, a nossa grande produção! São! São! Quinhentas mil morenas. Louras, cor de laranjas cem mil. Salve! ("Hino do carnaval brasileiro", de Lamartine Babo).

É oportuno esclarecer que esta última música referida foi gravada em 1939, em plena vigência do Estado Novo e da atuação do Departamento de Imprensa e Propaganda sobre as produções artísticas e culturais. Nesse período, além da divulgação intensa dos feitos de Getúlio Vargas, os órgãos de imprensa e as instituições governamentais pregavam o patriotismo, exigindo a louvação de ícones nacionais, entre eles o café e as florestas tropicais. Assim, não é surpreendente que os músicos tenham empregado, em suas produções artísticas, figuras retóricas para altear, ao mesmo tempo, a beleza física das mulheres e aspectos da natureza brasileira.

Nessa interpretação analítica do conteúdo dessas marchinhas levei em consideração a dicotomia entre natureza e cultura, que é tema caro às ciências sociais. Nas reflexões de Lévi-Strauss (2004), por exemplo, o estado da natureza está coligado ao instintivo, ao equipamento anatômico e à transmissão hereditária do material essencial para a sobrevivência do indivíduo e de sua espécie. Por outro lado, o estado de cultura supõe as regras sociais e as interdições, como o tabu do incesto que proíbe os casamentos endogâmicos. No entanto, sua referência principal para pensar as noções entre natureza e cultura dá-se pelas categorias de cru e de cozido.

O elemento cru seria a metáfora essencial da natureza, isto é, o alimento coletado em seu estado natural, sem passar por nenhum processo social pré- 
vio. Por seu turno, o cozido seria algo sociocultural por definição, posto englobar as técnicas que cada grupo social desenvolveu para obter, selecionar e preparar o alimento (ERICEIRA, 2009). Trazendo essa reflexão para as letras das marchinhas, pode-se inferir uma visão da mulher associada à natureza e do homem à cultura.

Das categorias temáticas criadas para fins de analisar o discurso das marchinhas coletadas para este trabalho, a mais frequente foi designada mulher-dominante. Essa categoria abrange todas as letras que, de algum modo, subvertem a ordem social androcêntrica que prevalecia no Rio de Janeiro no período histórico estudado. Em dez marchinhas examinadas, é a mulher que detém o domínio na relação. Contrariamente à dominação masculina que faz uso da agressividade e da gerência dos bens materiais para subjugar a mulher, esta recorre a seus atributos físicos e à economia afetiva para exercer o controle sobre os sentimentos e comportamentos masculinos. Vale esclarecer que entendo por economia afetiva a quantidade de investimento que uma mulher deposita em uma relação amorosa a fim de que possa ter os homens sob sua égide. As formas de dominação feminina presentes nas marchinhas são polissêmicas. Examinemos, então, alguns sentidos apreendidos no processo de interpretação de canções classificadas dentro do registro da mulher-dominante.

Se eu fosse o teu coió, me transformava em pó pra arranhar teu sapato devagar. O meu prestígio já caiu no meu país natal. Não tenho nenhum cargo eleitoral. Se eu fosse presidente, mandava pra você o Tesouro Nacional... (“Dá cá o pé... loura”, de Lamartine Babo).

Mulata, por teu encanto, muito eu levei na cabeça. Porém, agora eu duvido que isso outra vez aconteça. Do teu falado feitiço, eu pouco caso Ihe faço. Mandei fazer em São Paulo, mulata, um capacete de aço... Mulata, quando eu te vi, logo pedi anistia... ("Trem blindado", de Braguinha).

No primeiro fragmento, o eu (masculino) da marchinha emprega o termo coió, atualmente em desuso, para imaginar uma situação hipotética em que, sendo um namorado apaixonado, poderia cometer grandes tolices para conquistar a mulher, incluída a aceitação da subalterna condição de ser o pó do sapato dela. Nessa mesma marchinha, é notório ainda que o homem estava disposto a sacrificar-se economicamente para agradar a mulher desejada. Na segunda canção, inversamente à primeira, o compositor não aventa mais situações imaginárias, dedicando-se a narrar eventos concretos do passado. Seguindo o fluxo discursivo proposto pela marchinha, salta à observação a descrição do sofrimento masculino por causa de uma mulata. Embora encontrando mecanismos para se proteger contra os seus feitiços, o homem sucumbe, pedindo anistia, perante o que deno- 
mina de olhar fuzilante da mulher. Notamos, pois, que o homem consegue resguardar-se dos poderes mágicos da mulata, mas se considera impotente ante a sedução do seu olhar.

Em outras composições, é mais clara a assimetria entre os gêneros, posto ser a mulher que exerce o controle da relação, fazendo com que o homem solicite seu amor e sua atenção. Alguns versos esclarecem o que quero dizer sobre esta temática: "Linda morena, morena, que me faz penar. A lua cheia, que tanto brilha, não brilha tanto quanto o teu olhar... Teu coração é uma espécie de pensão, de pensão familiar à beira-mar. Oh, moreninha, não alugues tudo não, deixe ao menos o porão para eu morar" ("Linda morena”, Lamartine Babo).

No fragmento acima é evidente que é o ser feminino o dirigente da economia afetiva do relacionamento, cabendo ao homem conformar-se com o que lhe for concedido pela mulher. O compositor confessa ser seu coração cativo de uma mulher. Nessa relação desigual entre senhora e escravo, é este que deve implorar a Deus que sua senhora se apiede, concedendo-Ihe um beijo. Em outro conjunto de marchinhas, os compositores descrevem a amargura masculina, em razão de a mulher ter abandonado o homem logo após haver conquistado seu afeto. Vejamos algumas passagens:

A sorrir você me apareceu e as flores que você me deu. Guardei no cofre da recordação, porém depois você partiu pra muito longe e não voltou. E a saudade ficou, não quis abandonar meu coração. $A$ minha vida se resume, oh, dama das camélias, em duas flores sem perfume ("Dama das camélias", de Braguinha).

Segura esta mulher. Ela quer fugir. Roubou meu coração. Não pode escapulir, oi. Eu não sei o que vai ser! Meu amor, não sejas desmancha-prazer, oi ("Segura esta mulher", de Ari Barroso).

Na primeira marchinha, o compositor empregou categorias psicológicas, como saudade, recordação e coração, para transmitir a mensagem do desgosto masculino causado por uma mulher que o abandonou. Nos versos da segunda, revela-se uma espécie de desespero do homem ao perceber que mulher amada pretendia abandoná-lo. Indicando a assimetria no relacionamento, o homem alça a mulher à condição de responsável pelo seu prazer ou desprazer. É oportuno salientar ainda que, em outro espectro semântico englobado pela unidade temática "mulher-dominante", o homem se admite completamente consumido pelo amor que nutre pela mulher. Uma marchinha é bastante assertiva nesse sentido:

Ô balancê, balancê, quero casar com você. Entra na roda, morena, pra ver. Ô balancê, balancê. Quando por mim, você passa, fingindo 
que não me vê, meu coração quase se despedaça. No balancê, balancê. Você foi minha cartilha, você foi meu $A B C$, e por isso eu sou a maior maravilha. No balancê, balancê. Eu levo a vida pensando, pensando só em você ("Balancê", de Braguinha).

Essa marchinha marca, logo nos versos iniciais, a pretensão do homem de casar-se com a mulher. Ele sente seus sentimentos dilacerados quando a amada finge desprezá-lo. Sinalizando a inferioridade masculina, a canção enfatiza que a mulher ensinou todas as coisas da vida ao homem, por isso este leva a vida pensando nela. Em outra marchinha, a atribuição tradicional dos qualificativos sexuais, representando o homem como o ser ativo e insaciável para o sexo, ao passo que a mulher seria passiva e fria na cama, é invertida. Na canção, é o homem que se vê alarmado com a ardência sexual feminina. Transcrevo a seguir os versos dessa marchinha: “Queimei-me todo outro dia. Eu não sei o que seria: se o sol do mar ou o sol que trazes dentro do teu olhar. A tua ardência me assombra. Tu tens quarenta graus à sombra. Desta maneira, só mesmo te botando numa geladeira" (“Moreninha da praia", de Braguinha).

É pertinente sinalizar ainda que tão somente em uma canção entre as analisadas é o homem quem decide insubordinar-se às designações femininas. Isso porque sua própria integridade física estaria em perigo, caso aceitasse realizar o desejo da mulher. Eis a forma como o compositor tratou carnavalescamente essa temática:

Eu fui às touradas em Madri. E quase não volto mais aqui pra ver Peri beijar Ceci. Eu conheci uma espanhola natural da Catalunha. Queria eu tocasse castanhola e pegasse touro à unha. Caramba, caracoles, sou do samba, não me amoles. Pro Brasil, eu vou fugir. Isso é conversa para boi dormir ("Touradas em Madri", de Braguinha).

Convém observar que os fundamentos da recusa do homem em satisfazer o pedido feminino encontraram esteio em elementos da então recém-construída identidade brasileira. Relembro que essa marchinha foi produzida em plena vigência do Estado Novo, período em que as manifestações populares foram valorizadas positivamente, sendo alavancadas ao patamar de ícones nacionais. $\mathrm{Na}$ canção em questão, os compositores acionaram o samba como índice de pertencimento à cultura brasileira, logo, não poderiam concretizar os pedidos da espanhola, pautados em costumes da Catalunha.

\section{CONSIDERAÇÕES FINAIS}

A análise do discurso dessas marchinhas teve como fundo a cidade do Rio do Janeiro das décadas de 1930 e 1940. A então capital federal vivia a efervescên- 
cia do cinema, do rádio e do teatro de revista. Por meio dessas manifestações artísticas as marchinhas popularizavam-se junto ao grande público, ávido de divertimento e desejoso de conhecer seus artistas favoritos. Por outro lado, a vigência da ditadura getulista tolhia a livre expressão do pensamento ao mesmo tempo em que estimulava as demonstrações de patriotismo.

Nesse cenário, em que se discutia a apropriação da cultura popular pelas instâncias governamentais e se valorizavam as produções mestiças, as relações entre os homens e mulheres eram também tema recorrente no cotidiano da cidade. Embora as mulheres tivessem obtido conquistas sociais, como o direito ao voto e à inserção em algumas atividades profissionais, a maioria dos discursos da época era conservadora, assegurando direito de fala e de circulação nos espaços públicos preferencialmente aos homens. Historicamente, sabe-se que quem é autorizado a falar é investido de um poder advindo do lugar que ocupa na sociedade. Essa autorização é legitimada em função da posição social, da raça e do gênero daqueles que proferem os discursos hegemônicos. No período getulista, o sujeito imbuído do direito de falar era prioritariamente do segmento médio, branco e pertencente ao gênero masculino.

Um dado relevante a ser mencionado sobre as músicas de carnaval é que elas são polissêmicas, isto é, cada marchinha traz em seu bojo vário sentidos. Optei por delinear as visões que apareciam com mais frequência nas letras examinadas. Assim, um primeiro aspecto destacável é a negação da mulher como ser social, ou seja, reiteradamente, ela foi representada por conteúdos biológicos ou naturais. Foi com essa compreensão de ver o ser feminino por aspectos biológicos ou naturais que diversas marchinhas foram compostas. Na acepção dos compositores, a mulher ideal era apontada como bela, jovem, capaz de despertar o interesse sexual masculino, mas que, ao mesmo tempo, fosse submissa e fiel ao homem.

Nesse viés, as marchinhas serviam como espécie de veículo de comunicação por meio do qual os setores médios do Rio de Janeiro podiam fazer apelo às normas e às repreensões sociais para fins de manutenção da dominação masculina na sociedade carioca da época. A mulher que saía sozinha à noite desacompanhada ou que fizesse algo que desagradasse ao marido poderia ter duas punições: a difamação ou a agressão física.

Nem todas as visões concernentes às mulheres nas letras das canções investigadas apontam para uma assimetria em favor do masculino nas relações de gênero. Na maioria das marchinhas, o fato de a mulher exercer o controle da economia dos afetos na relação obrigava o homem a permanecer sob sua égide. Nessas canções era o ser feminino quem decidia pelo começo, pela continuidade ou 
pelo fim do relacionamento. Em certa medida, a decisão feminina era a responsável pela alegria ou pelo sofrimento psicológico masculino. Notadamente, porém, essa visão da mulher ocupando o papel dominante na relação pautava-se em representações que atrelavam o universo feminino ao domínio dos afetos; em oposição, portanto, ao mundo do intelecto e do trabalho, que permaneceriam prerrogativas masculinas (BOURDIEU, 1999). Baseando-me no exposto, é possível afirmar que, sob o ângulo dos compositores de marchinhas, não havia nem perfil feminino único, nem modelo-padrão de relacionamentos entre homens e mulheres. As relações de gênero podiam acontecer sob a dominação masculina, quando o homem fazia uso de seu poder econômico, de sua força física ou dos costumes da época, que apregoavam a submissão feminina. Por outro lado, a dominação feminina se consubstanciava quando a mulher recorria a seus dotes físicos, a seu charme e a seu poder de despertar o desejo sexual nos homens para tê-los, conforme a sua vontade.

\section{REFERÊNCIAS BIBLIOGRÁFICAS}

ALENCAR, Edgar. A história do carnaval carioca através da música. Rio de Janeiro: Francisco Alves, 1979.

BAKHTIN, Mikhail. A cultura popular na Idade Média e no Renascimento: o contexto de François Rabelais. São Paulo/Brasília: Eusp/Hucitec, 1996. . Marxismo e filosofia da linguagem. São Paulo: Hucitec, 1986.

BOURDIEU, Pierre. A dominação masculina. Rio de Janeiro: Bertrand Brasil, 1999.

CASTRO, Alexandre C. Olhai os delírios no conto: análise dos temas psicológicos nos contos de Machado de Assis. Tese (doutorado em psicologia social) - Universidade do Estado do Rio de Janeiro, Instituto de Psicologia,, Rio de Janeiro, 2005.

DAMATTA, Roberto. Conta de mentiroso: sete ensaios de antropologia brasileira. Rio de Janeiro: Rocco, 1994.

DINIZ, Edinha. Chiquinha Gonzaga: uma história de vida. Rio de Janeiro: Rosas dos Ventos, 1999.

ERICEIRA, Ronald Clay dos Santos. A mulher é a tal: visões de compositores de marchinhas carnavalescas sobre as mulheres no Rio de Janeiro dos anos de 1930 e 1940. Tese (doutorado em psicologia social) - Universidade do Estado do Rio de Janeiro, Instituto de Psicologia, Rio de Janeiro, 2010.

. A reconstrução do passado da Portela na rede mundial de computadores e nas rodas de samba. Tese (doutorado em ciências humanas - antropologia cultural) - Universidade Federal do Rio de Janeiro, Instituto de Filosofia e Ciências Sociais, Rio de Janeiro, 2009.

FREYRE, Gilberto. Casa-grande e senzala. Rio de Janeiro: J. Olympio, 1981. 
LÉVI-STRAUSS, Claude. Totemismo hoje. Petrópolis: Vozes, 2004.

MORAES, Eneida de. História do carnaval carioca. Rio de Janeiro: Civilização Brasileira, 1959.

SEVERIANO, Jairo. Yes, nós temos Braguinha. Rio de Janeiro: Funarte-Instituto Nacional de Música, 1991.

TINHORÃO, José Ramos. Música popular: um tema em debate. São Paulo: Editora 34, 1997.

Ronald Clay dos Santos Ericeira é professor adjunto do Departamento de Psicologia da UFRRJ, psicólogo, mestre em ciências sociais pela UFMA, doutor em ciências humanas (antropologia cultural) pela UFRJ e doutor em psicologia social pela UERJ.

Recebido em: 20/03/2013

Aceito em: 16/04/2013 
